\title{
Trends in spectrally resolved outgoing longwave radiation from 10 years of satellite measurements
}

\author{
Simon Whitburn $\mathbb{D}^{1 凶}{ }^{\bowtie}$, Lieven Clarisse $\mathbb{E}^{1}$, Marie Bouillon ${ }^{2}$, Sarah Safieddine ${ }^{2}$, Maya George $\mathbb{E}^{2}$, Steven Dewitte ${ }^{3}$, \\ Hélène De Longueville', Pierre-François Coheur ${ }^{1}$ and Cathy Clerbaux $\mathbb{D i D}^{1,2}$
}

In recent years, the interest has grown in satellite-derived hyperspectral radiance measurements for assessing the individual impact of climate drivers and their cascade of feedbacks on the outgoing longwave radiation (OLR). In this paper, we use 10 years (2008-2017) of reprocessed radiances from the infrared atmospheric sounding interferometer (IASI) to evaluate the linear trends in clear-sky spectrally resolved OLR (SOLR) in the range $[645-2300] \mathrm{cm}^{-1}$. Spatial inhomogeneities are observed in most of the analyzed spectral regions. These mostly reflected the natural variability of the atmospheric temperature and composition but longterm changes in greenhouse gases concentrations are also highlighted. In particular, the increase of atmospheric $\mathrm{CO}_{2}$ and $\mathrm{CH}_{4}$ led to significant negative trends in the SOLR of -0.05 to $-0.3 \%$ per year in the spectral region corresponding to the $v_{2}$ and the $v_{3} \mathrm{CO}_{2}$ and in the $v_{4} \mathrm{CH}_{4}$ band. Most of the trends associated with the natural variability of the OLR can be related to the El Niño/Southern Oscillation activity and its teleconnections in the studied period. This is the case for the channels most affected by the temperature variations of the surface and the first layers of the atmosphere but also for the channels corresponding to the $v_{2} \mathrm{H}_{2} \mathrm{O}$ and the $v_{3}$ $\mathrm{O}_{3}$ bands.

npj Climate and Atmospheric Science (2021)4:48; https://doi.org/10.1038/s41612-021-00205-7

\section{INTRODUCTION}

The Earth's climate is closely linked to the flow of energy in and out of the Earth-atmosphere system. At equilibrium, the outgoing longwave radiation (OLR) and the reflected shortwave radiation (RSW) $\left(\mathrm{W} \cdot \mathrm{m}^{-2}\right)$ at the top of the atmosphere (TOA) compensate the Incoming Solar Radiation (ISR) on average. Any perturbation of this balance due to a variation of the climate drivers (e.g. greenhouse gases), known as a radiative forcing, leads to a climate feedback which attempts to bring the radiation budget back to equilibrium ${ }^{1}$. A good understanding of the Earth-atmosphere system and of its long-term changes therefore requires an accurate evaluation of the radiative effects of the climate drivers and feedbacks on the OLR. Considerable improvements have been achieved in the last four decades through the exploitation of spectrally integrated OLR from dedicated broadband instruments (e.g. refs. ${ }^{1-6}$ ). Different methods, such as the radiative kernel technique $^{7,8}$ and the partial radiative perturbation ${ }^{9}$, have been developed to evaluate the contribution of individual variables to the changes in the OLR from broadband measurements. While these techniques are very powerful, they rely on an accurate knowledge of the different parameters of interest. For instance, to study the impact of $\mathrm{O}_{3}$ on the OLR, these techniques exploit infrared satellite retrievals or model outputs, which can both be subject to strong regional biases and inaccuracies.

Independent constraints can, in principle, be obtained from spectrally resolved OLR (i.e. the integrand of broadband OLR, in units of $\left.\mathrm{W} \cdot \mathrm{m}^{-2} \cdot\left(\mathrm{cm}^{-1}\right)^{-1}\right)$ derived from infrared hyperspectral sounders, which give access to the spectral signature of individual climate processes and feedbacks. While the potential for using spectrally resolved OLR (hereafter abbreviated as SOLR) for the study of climate change has been known for some time (e.g. refs. $\left.{ }^{10,11}\right)$, the interest for these measurements has only grown relatively recently with the advent of stable multi-year observations ${ }^{12}$. Among the latest achievements, important results were obtained by refs. ${ }^{13,14}$ and ${ }^{15,16}$ from the measurements of the Atmospheric Infrared Sounder (AIRS, aboard NASA's Aqua satellite $\left.{ }^{17}\right)$. In particular, they identified a series of biases in climate models that compensated each other partially, and did not show up in comparisons with broadband fluxes. More recently, based on an analysis of 10 years of AIRS global-mean radiances, Pan et al. ${ }^{18}$ calculated significant cooling trends in the carbon dioxide $\left(\mathrm{CO}_{2}\right) v_{2}$ band for channels sensitive to the lower and the mid-stratosphere. Clear differences were highlighted in trends derived from synthetic AIRS radiances computed by considering the output of a free-running general circulation model (GCM) and the European Centre for Medium-Range Weather Forecasts (ECWMF) reanalysis data set (ERA-Interim), confirming the challenges in accurately modeling and assimilating the stratospheric climate.

The infrared atmospheric sounding interferometer $\left(\left.I A S\right|^{19,20}\right.$ ) on board the Metop satellites is a hyperspectral sounder like AIRS, which has the advantage of covering the $645-2760 \mathrm{~cm}^{-1}$ thermal infrared region without any gaps, which makes it well suited for detecting changes in the Earth's SOLR related to trace gases variations. Because of their different overpass time (9.30 versus 13.30 a.m. and p.m. local time for IASI and AIRS, respectively), the joint exploitation of the measurements from the different infrared instruments (also including the Cross-track Infrared Sounder (CrIS) on Suomi NPP which was launched in $2011^{21}$ but whose measurements were never used to date to derived SOLR) could provide meaningful information on, for example, the diurnal cycle of the SOLR or for the confirmation of the variations observed in the SOLR. Since its launch in 2006, IASI has shown a very good stability over time and its measurements provide a good fundamental climate data record ${ }^{22,23}$. Among others, IASI is used as a reference for the inter-calibration of infrared sensors by the Global Space-Based Inter-Calibration System ${ }^{24,25}$. Brindley et al. ${ }^{26}$

${ }^{1}$ Spectroscopy, Quantum Chemistry and Atmospheric Remote Sensing (SQUARES), Université libre de Bruxelles (ULB), Brussels, Belgium. ${ }^{2}$ LATMOS/IPSL, Sorbonne Université, UVSQ, CNRS, Paris, France. ${ }^{3}$ Royal Meteorological Institute of Belgium, Brussels, Belgium. ${ }^{凶}$ email: simon.whitburn@ulb.be 
were the first to exploit the IASI measurements to study interannual variability in the radiance based on 5 years of observations. Variations were found to be small enough to allow the identification of robust changes in regions affected by feedback processes. Right after, Bantges et al. ${ }^{27}$ focused on the detection of changes in the Earth's OLR spectrum by comparing radiance spectra of the interferometric monitor for greenhouse gases (IMG), the interferometric infrared spectrometer (IRIS) and the IASI sounder. Among others, clear signatures were identified in the spectra related to increases in well-mixed greenhouse gases. Here, we analyze the trends in 10 years (2008-2017) of IASI clearsky SOLR retrieved from a dedicated algorithm recently developed by Whitburn et al. ${ }^{28}$. Considering the relatively short time period, this study can be seen as a proof of concept in which one of the primary goals is to evaluate the sensitivity of the IASI-derived SOLR product to detect and quantify small changes in the SOLR and to show how these can be linked to changes in surface and atmospheric conditions. In particular, we address the following questions:

- Can statistically significant SOLR trends be detected from IASI channels that are sensitive at different altitudes in the troposphere and in the stratosphere? What is the magnitude of the changes?

- Can these statistically significant trends be related to known changes in climate processes?

- Can the effect of increasing greenhouse gases be detected on the SOLR in the 10 years of IASI measurements?

The data and the method for the trends estimation are detailed in section 4.

\section{RESULTS \\ Figures}

Figure 1a shows the zonal SOLR trends at a resolution of $0.25 \mathrm{~cm}^{-1}$. For the sake of clarity, these are expressed as a percentage of the average SOLR in the year 2008 (percentage per year). Indeed, as the radiance decreases with the wavenumber in the range $[6452300] \mathrm{cm}^{-1}$, trends presented in absolute values become lower for increasing wavenumber. Note that the choice of the reference year matters very little for the calculation of trends, as the relative changes in SOLR are very small. Stippling indicate trends not significantly different from zero. An upper bound was set at $75^{\circ}$ North and South of the Equator since we observed that the cloud filter used to identify clear-sky scenes in the SOLR retrieval algorithm becomes less accurate at high latitudes and also because the surface occupied by seas is lower at the poles. The area-weighted mean of the zonal LT for the tropical region $\left(24^{\circ} \mathrm{S}-24^{\circ} \mathrm{N}\right)$ and the Northern and Southern high latitudes $\left(60^{\circ}-75^{\circ} \mathrm{N}\right.$ and $\left.\mathrm{S}\right)$ are shown as well (Fig. $1 \mathrm{~b}, \mathrm{~d}$, respectively). These allow assessing the trends on a more global scale and to identify small changes in the SOLR that might not appear at the zonal scale. The associated confidence limit (shaded area) were calculated in the same way, i.e. averaged from the $95 \%$ lower and upper limit of the zonal LT. From a radiation budget perspective, Fig. $1 \mathrm{~b}, \mathrm{~d}$ are also presented on Supplementary Fig. 1 in units of $\mathrm{W} \cdot \mathrm{m}^{-2}$ per year.

To help the interpretation of the results, we also evaluated at what altitudes the largest changes in radiation occur (in absorption or emission) by calculating the relative change (in percentage) of the Earth's radiation after passage through $1-\mathrm{km}$ thick layers of the atmosphere: $\left(L_{i+1}-L_{i}\right) /\left(L_{i}\right) \times 100$, with $L_{i}$ the Earth's radiance $\left(\mathrm{W} \cdot \mathrm{m}^{-2} \cdot\left(\mathrm{cm}^{-1}\right)^{-1} \cdot \mathrm{sr}^{-1}\right)$ at the top of the layer $i$. The change in each layer (\%) was determined for a tropical (Fig. 1c) and a subarctic (Fig. 1e) standard atmosphere ${ }^{29}$ from a set of IASI synthetic spectra calculated with the Atmosphit line-by-line radiative transfer code $^{30}$.
In addition to the zonal trends, we also calculated the global LT on a $2^{\circ} \times 2^{\circ}$ grid for a set of selected channels sensitive to different altitudes, as well as global temperature LT derived from the ERA5 reanalysis dataset over the same time-period ${ }^{31}$ at different levels of pressure. The calculation of the temperature LT was made from 24-hourly data that were averaged per day. Note that considering temperatures interpolated at 9.30 a.m. instead does not affect the results. These global LT distributions of SOLR and temperature are shown in Fig. 2 and are used to support our analysis of Fig. 1.

\section{Surface and lower troposphere}

In the atmospheric window regions $\left(795-970 \mathrm{~cm}^{-1}\right.$, $1070-1230 \mathrm{~cm}^{-1}$, and $2090-2170 \mathrm{~cm}^{-1}$ ), where the atmosphere is mostly transparent, the changes in the SOLR reflect principally the changes in the surface temperature $\left(T_{s}\right.$, compare Fig. 2a with Fig. 2g); and, in selected microwindows, also in $\mathrm{H}_{2} \mathrm{O}$. The 2008-2017 period was characterized by two strong La Niña episodes in 2007-2008 and 2010-2011 and a strong El Niño episode in 2015-2016 ${ }^{32}$, which coincided with cool and warm Pacific Decadal Oscillation $\left(\mathrm{PDO}^{33}\right)$ phases $^{34}$, respectively. In the tropics and at mid-latitudes $\left(<45^{\circ} \mathrm{N}\right.$ and $\left.\mathrm{S}\right)$, these led to a cooler mean sea surface temperature (SST) in the beginning and a warmer mean SST in the end of the period which explain the positive LT (about +0.03 to $+0.05 \%$ per year, or +0.5 to $+1.3 \times$ $10^{-4}$ in $\mathrm{W} \cdot \mathrm{m}^{-2}$ per year) (Fig. 1a, b). The same evolution was reported by Loeb et al. ${ }^{9}$ in longwave TOA flux anomalies $\left(\mathrm{W} \cdot \mathrm{m}^{-2}\right)$ with low anomalies observed before 2014, followed by strong positive anomalies until 2017. The importance of El Niño and PDO on the LT in the window regions is verified on the global distribution of the LT for the SOLR integrated over the [795-970 $\mathrm{cm}^{-1} ; 1070-1230 \mathrm{~cm}^{-1}$ ] window region (Fig. 2a) and for the ERA5 $\mathrm{T}_{S}$ (Fig. 2g) where typical El Niño/Southern Oscillation (ENSO) and PDO patterns can be clearly identified over the Pacific Ocean (boxes 1 and 3$)^{35}$. Other warming trends that could not be related to a particular climate phenomenon are observed in the tropics along the west coast of the Pacific Ocean and contribute also to the zonal mean positive LT. Note that it can be verified that a change in surface temperature results in a relative change in radiation flux that increases quasi-linearly with wavenumber as illustrated with the straight line drawn on Fig. $1 \mathrm{~b}, \mathrm{~d}$.

In the northern hemisphere between $45^{\circ}$ and $60^{\circ}$, LT do not differ significantly from zero in the window channels (Fig. 1a). However, when looking at Fig. 2a, we find an important spatial heterogeneity with both cooling and warming regions. Two large areas that exhibit strong negative trends are identified. One is located in the North Atlantic (about $-0.15 \%$ per year, extending up to $\sim 68^{\circ} \mathrm{N}$ ) and can be related to a particular phenomenon called the North Atlantic Warming Hole (NAWH) (Fig. 2a, box 2), likely due to the melting of the Greenland ice sheet and affecting the Atlantic meridional overturning circulation (AMOC) in the same region ${ }^{36}$. The second one (left part of box 1 ) is found in the Western Pacific and is part of the PDO pattern ${ }^{35}$. These two cooling areas are counterbalanced by the strong PDO warming pattern in the Eastern Pacific. Above $60^{\circ} \mathrm{N}$, the zonal LT (Fig. 1a) become negative (between -0.1 and $-0.4 \%$ per year, about $-5 \times$ $10^{-4}$ to $-2.5 \times 10^{-4} \mathrm{~W} \cdot \mathrm{m}^{-2}$ per year). Up to $68^{\circ} \mathrm{N}$, these are driven by the cooling in the North Atlantic because of the relative importance of the region in the total area occupied by seas at these latitudes $(\sim 65 \%)$. Oddly, above $68^{\circ} \mathrm{N}$, the zonal trends remain negative while Fig. 2a shows a dominance of positive LT. However, the zonal LT at these latitudes are not trustworthy (uncertainty close to $100 \%$ ) due to a low number of observations (partly because of a lower accuracy of the cloud filter) and a higher seasonality and local variations of the SOLR.

In the Southern Hemisphere (below $45^{\circ}$ ), different warming and cooling areas are also observed. Over the South Atlantic and Pacific (box 4, Fig. 2a), these likely reflect the activity of the 
(a)

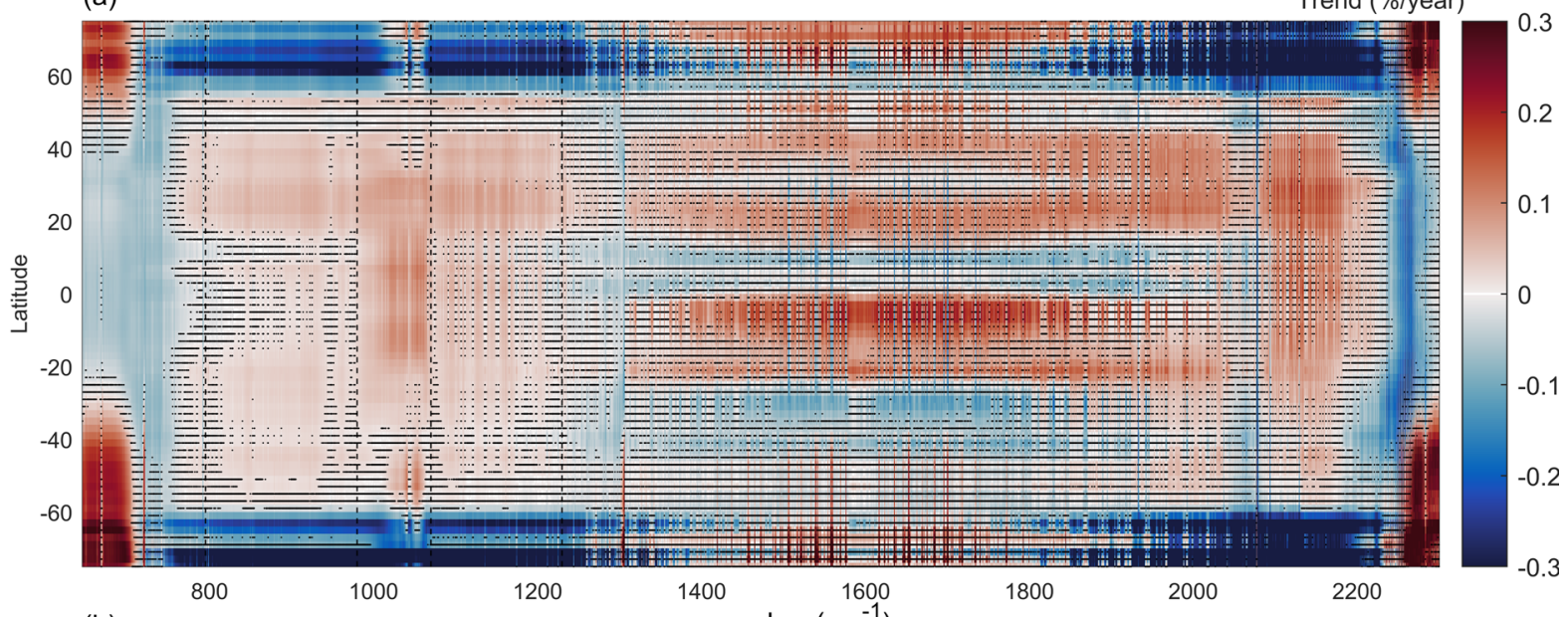

(b)

wavenumber $\left(\mathrm{cm}^{-1}\right)$
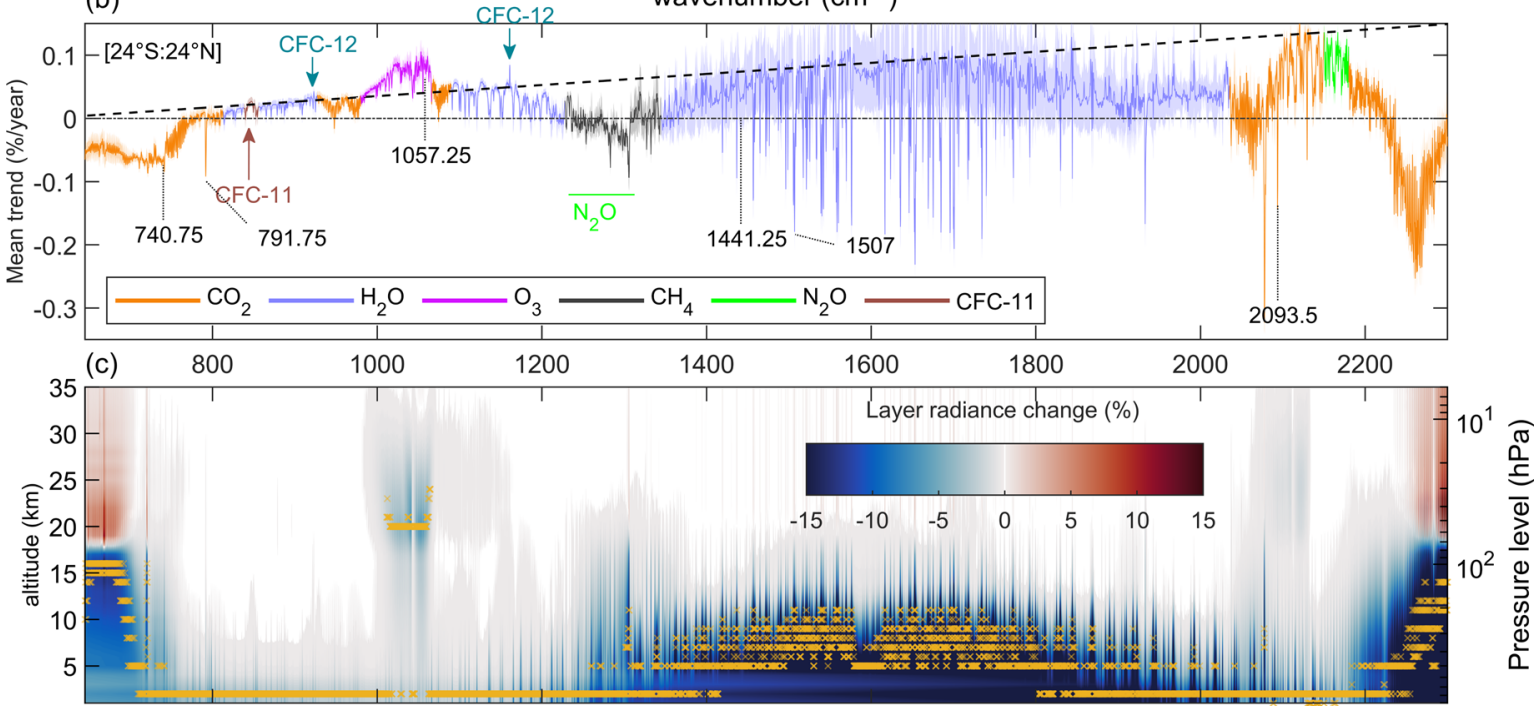

(d)
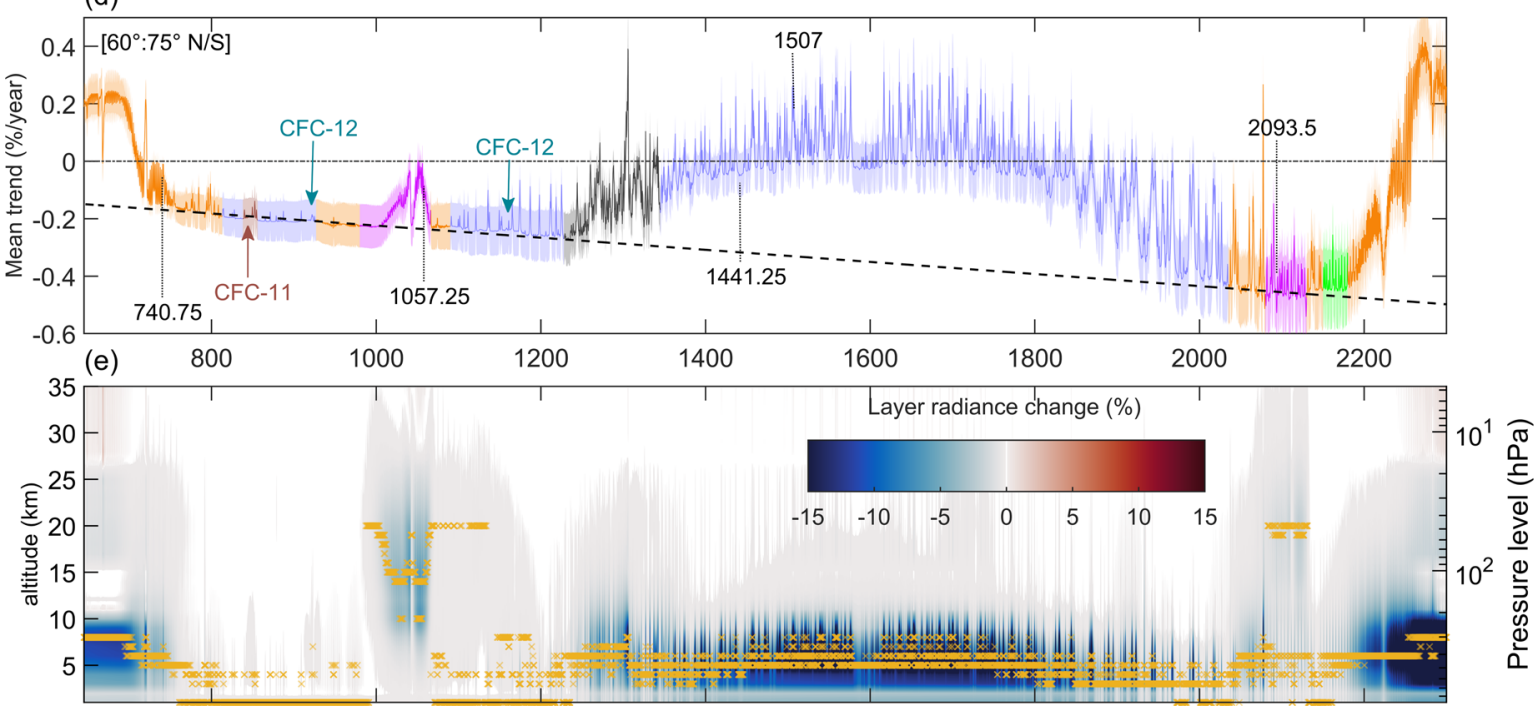

Fig. 1 Linear trends in the SOLR for all IASI channels between 645 and $2300 \mathrm{~cm}^{-1}$. a $2^{\circ}$ zonal mean SOLR linear trends from 10 years (2008-2017) of IASI-derived clear-sky SOLR (percentage per year). Dots indicate trends non-statistically significantly different from zero at the $95 \%$ confidence level. b Area-weighted global mean trends for the tropical region $\left(24^{\circ} \mathrm{S}-24^{\circ} \mathrm{N}\right)$ with their $95 \%$ confidence limits (shaded area). The straight dotted line illustrates the quasi-linear increase of the relative change in radiation flux with wavenumber in response to a surface temperature increase. c Radiance changes (\%) as a function of altitude for a tropical standard atmosphere. The orange crosses show the altitude of the peak of sensitivity. $\mathbf{d}$ Same as panel b, but for high-latitude regions $\left(60^{\circ}-75^{\circ} \mathrm{N}\right.$ and S). e Same as panel $\mathbf{c}$ but for a subarctic standard atmosphere. 

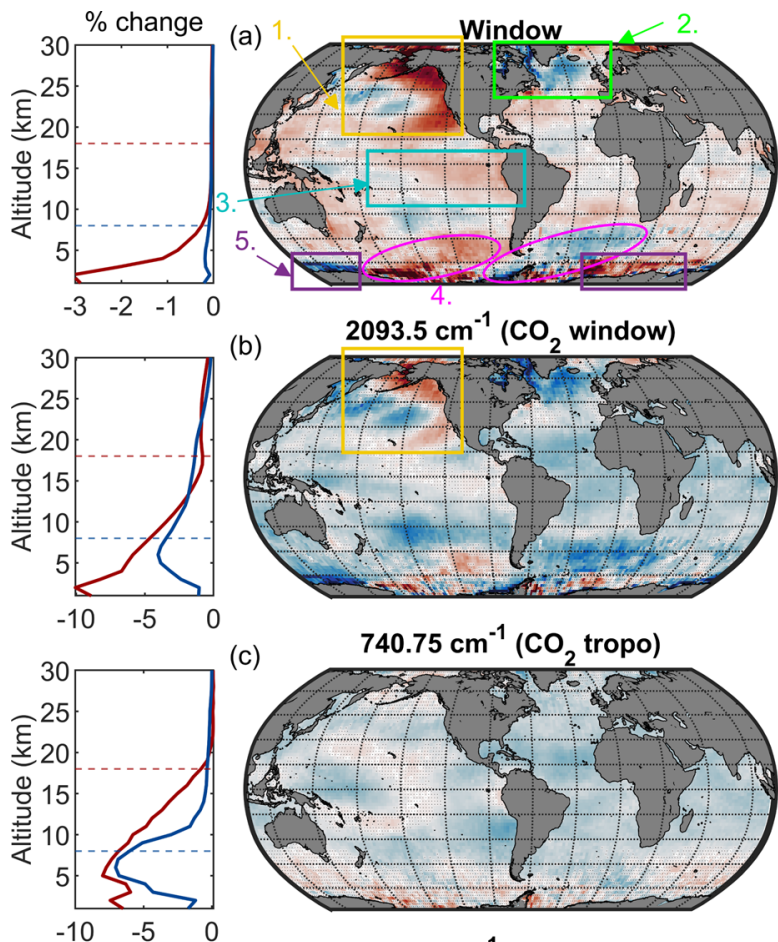

(c)
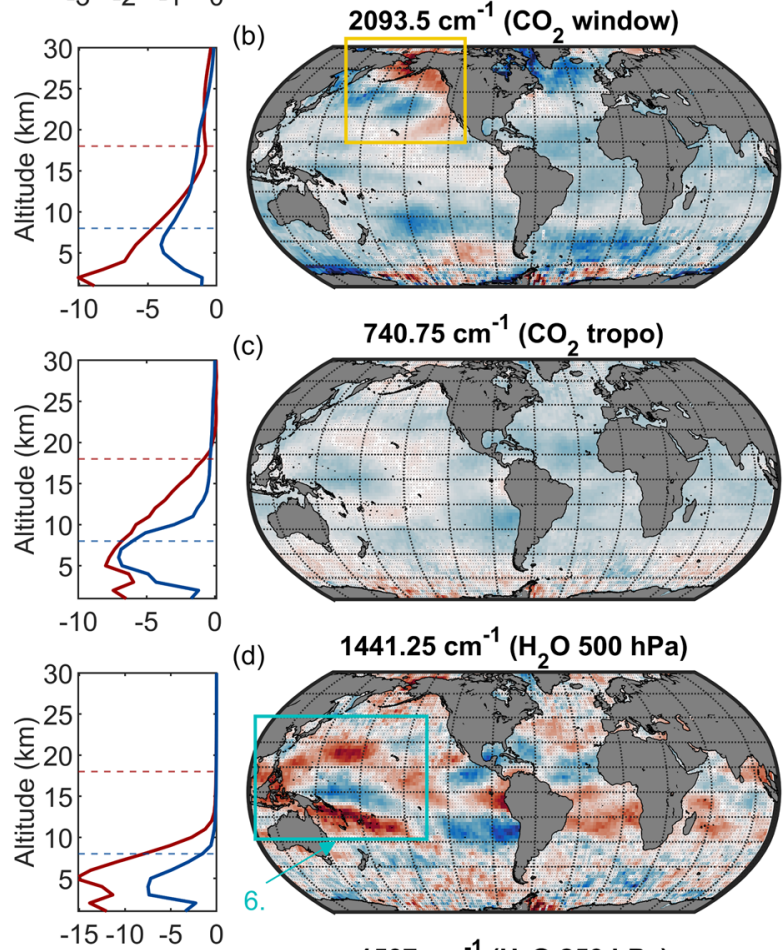

(d)
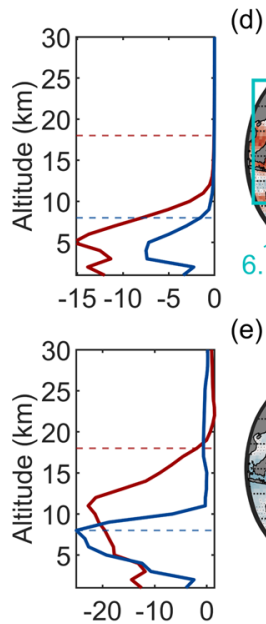

(e)
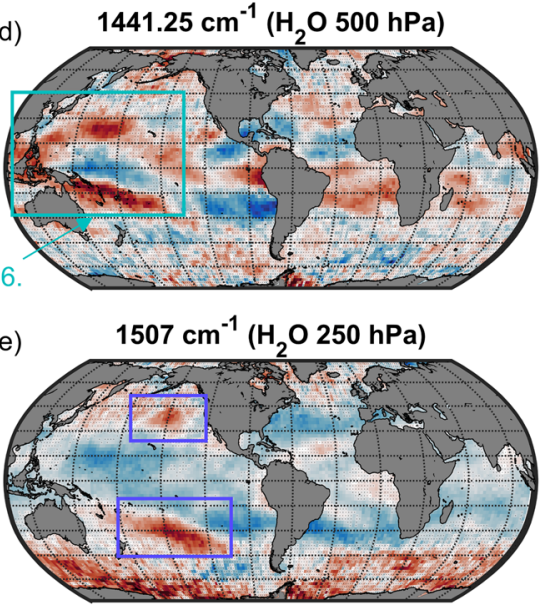

(i)
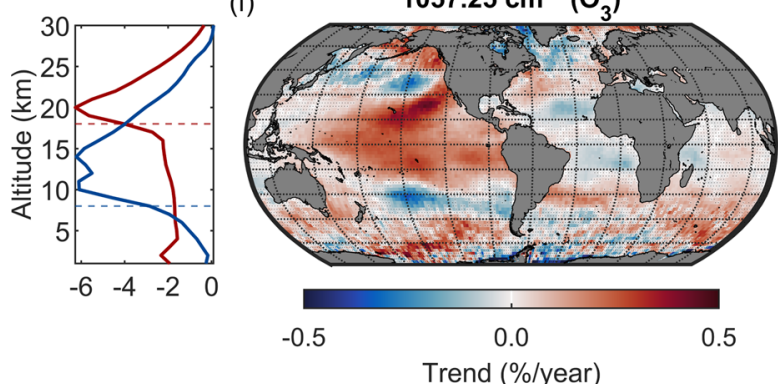
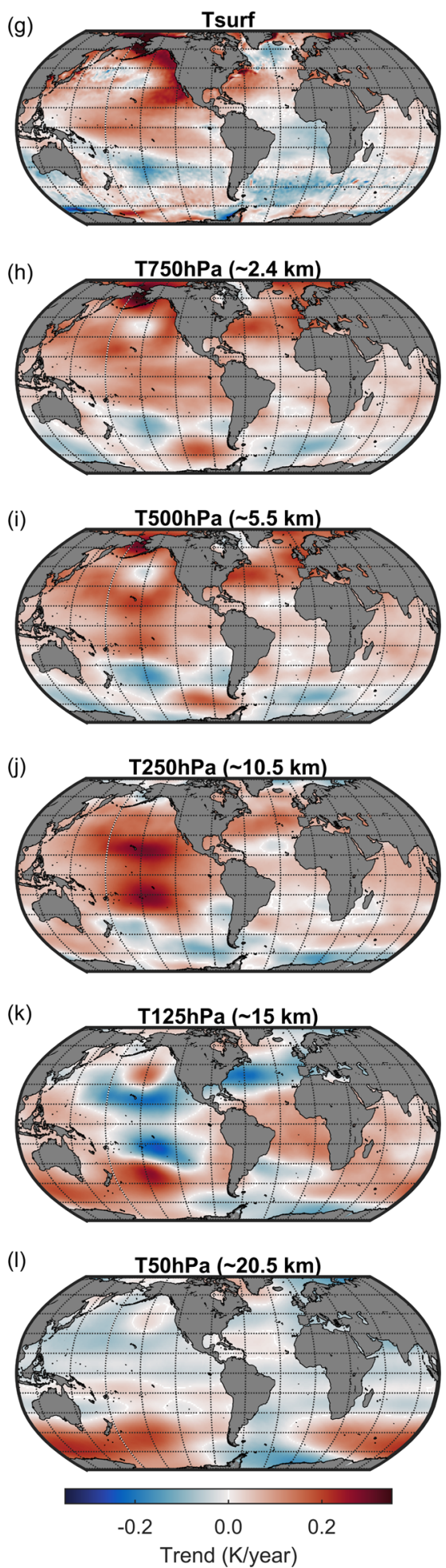

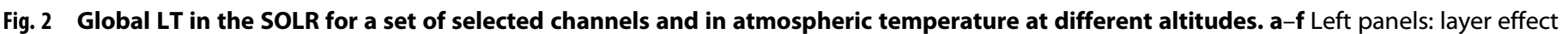

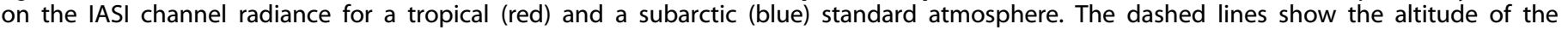

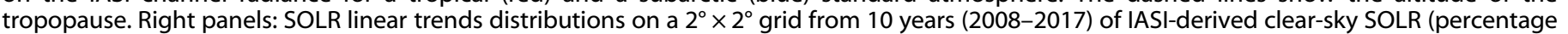

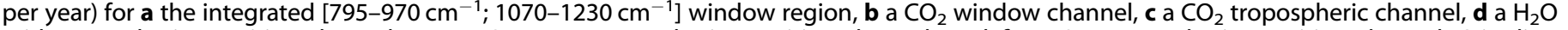

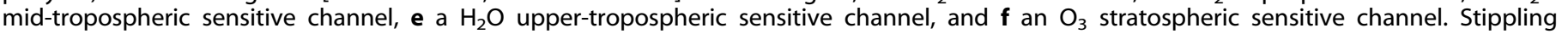

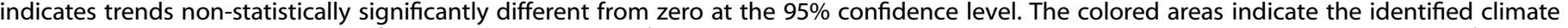

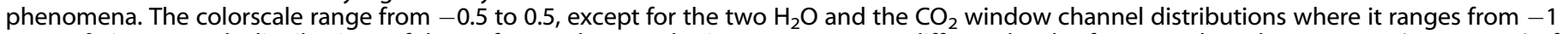

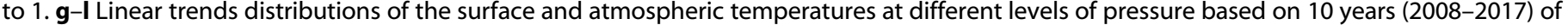
ERA5 reanalysis dataset on a $1^{\circ} \times 1^{\circ}$ grid $^{31}$. Corresponding altitudes are indicated as well. 
Antarctic Dipole (ADP) which corresponds to a high-latitude climate phenomenon in the air-sea-ice system that is strongly influenced by the ENSO variations ${ }^{37}$. During El Niño events, positive (negative) sea surface temperature anomalies generally occur in the South Pacific (Atlantic). The patterns are similar but opposite during La Niña events. Because of the two La Niña events in the beginning and the strong El Niño in the end of the studied period, the dipole exhibits here positive LT in the South Pacific and negative LT in the South Atlantic. Strong positive and negative LT are also observed close to the Antarctic shores in the Indian Ocean (between $0^{\circ}$ and $90^{\circ} \mathrm{E}$ ) and in the Western Pacific Ocean (between $100^{\circ}$ and $150^{\circ} \mathrm{E}$ ), respectively (box 5, Fig. 2a). The reason for these cooling and warming trends is unclear and reflects a variation in the air-sea-ice system, possibly linked to the activity of the ADP as well. As for the Northern Hemisphere, the positive and negative LT compensate each other between $50^{\circ}$ and $60^{\circ} \mathrm{S}$, resulting in zonal LT not significantly different from zero (Fig. 1a). Again, surprisingly, the zonal LT become negative below $60^{\circ} \mathrm{S}$ while positive LT dominate at these latitudes on the global distribution (Fig. 2a) and should therefore be considered with care. The strong regional disparities in the LT evidenced here for both the Northern and the Southern Hemisphere that do not show up in the zonal mean highlight well the limits of the approach if it is not completed by an analysis based on global distributions. With the follow-up of the IASI mission, longer time series will become available in the near future and allow to better evaluate and characterize the climate processes at high latitudes in the Northern and the Southern Hemisphere.

When analyzing the LT in the window regions on Fig. 1a for each channel individually, we find a fine spectral structure (LT slightly less positive or negative than on average) corresponding to low tropospheric $\mathrm{CO}_{2}$ and $\mathrm{H}_{2} \mathrm{O}$ absorption lines which reflect the changes in their atmospheric concentrations. This becomes more evident on the area-weighted average trends (Fig. 1b, d). For $\mathrm{CO}_{2}$, the increasing concentrations in the atmosphere increase the amount of Earth's radiation absorbed and thus reduce the OLR ${ }^{10}$. This is confirmed when looking at the global LT distribution for the strong $2093.5 \mathrm{~cm}^{-1} \mathrm{CO}_{2}$ channel (Fig. 2b) mostly sensitive to the first layers of the atmosphere in the tropics and at mid-latitudes (Fig. 2b, left panel). In contrast to the temperature changes close to the surface (Fig. $2 \mathrm{~g}$ ), the LT are mainly negative, except over the Northern Pacific Ocean, where a positive PDO pattern remains (Fig. 2b, orange box). For the $\mathrm{H}_{2} \mathrm{O}$ window channels, the change in SOLR is closely linked with the changes of the $T_{s}$ and atmospheric temperature $\left(T_{a}\right)$ as a consequence of the Clausius-Clapeyron process ${ }^{38}$. In the tropics (at high latitudes), the increase (decrease) of $\mathrm{T}_{s}$ leads to an increase (decrease) of the specific humidity and, therefore, to an increase (decrease) of the absorbed radiations (Fig. $1 \mathrm{~b}, \mathrm{~d})^{10,38}$. In addition to $\mathrm{CO}_{2}$ and $\mathrm{H}_{2} \mathrm{O}$, spectral features related to the decrease in the CFC-11 and the CFC-12 atmospheric concentrations (two ozone-depleting substances targeted by the 1987 Montreal protocol, World Meteorological Organisation ${ }^{39}$ ) can also be observed on the average trends in the window region, with peaks in the LT observed around $847 \mathrm{~cm}^{-1}$ (CFC-11) and $\sim 923 \mathrm{~cm}^{-1}$ and $\sim 1161 \mathrm{~cm}^{-1}$ (CFC-12). Conversely, the effect of increasing $\mathrm{N}_{2} \mathrm{O}$ concentrations does not appear on the LT, where most of the changes in the $v_{1} \mathrm{~N}_{2} \mathrm{O}$ band (around $2224 \mathrm{~cm}^{-1}$ ) are likely hidden by other overlapping atmospheric variations (probably $\mathrm{CO}_{2}$ and $\mathrm{H}_{2} \mathrm{O}$ ).

\section{Mid-, upper troposphere and stratosphere}

For the channels peaking in the mid- and upper troposphere, and in the stratosphere (Fig. 1c, e), corresponding mainly to the regions of absorption of $\mathrm{H}_{2} \mathrm{O}, \mathrm{CO}_{2}, \mathrm{CH}_{4}$, and $\mathrm{O}_{3}$, the $\mathrm{LT}$ result from both the increase of greenhouse gases concentrations and the atmospheric temperature changes. The latter are determined by dynamical processes that originate mostly from changes in SST in the tropics. A rise of SST (mainly related to ENSO cycle here) is known to enhance the deep convection and to cause a strengthening of the Brewer-Dobson circulation (BDC) $)^{40}$. In the tropics, this translates to a warming of the troposphere but a cooling of the lower stratosphere ${ }^{41-44}$. This cooling is also reinforced by the impact of the increase in $\mathrm{CO}_{2}$ concentrations ${ }^{45}$. Conversely, at high latitudes (mostly in the Southern Hemisphere), the strengthening of the BDC induces a stronger downward motion which leads to a warming of the stratosphere through adiabatic heating $40,43,44,46$. This warming is also reinforced by the effect of the recovery of the ozone hole ${ }^{47}$. These effects are observed in the sequence of Fig. $2 \mathrm{~h}-\mathrm{l}$, where a progressive inversion of the sign of the LT can be seen on the atmospheric temperature distributions when moving from the troposphere to the stratosphere (starting at $17-18 \mathrm{~km}$ of altitude in the tropics and at $8-9 \mathrm{~km}$ in the Arctic regions).

We first focus on the changes in the tropical and mid-latitude regions. Immediately obvious on Fig. $1 \mathrm{a}, \mathrm{b}$ are the systematic negative trends observed in the $v_{2}$ (below $795 \mathrm{~cm}^{-1}$ ) and the $v_{3}$ (after $2200 \mathrm{~cm}^{-1}$ ) $\mathrm{CO}_{2}$ absorption bands and, to a lesser extent, in the $v_{4} \mathrm{CH}_{4}$ band (around $1306 \mathrm{~cm}^{-1}$ ) which range from about -0.05 to $-0.3 \%$ per year. Similar negative patterns were also reported by ${ }^{48}$ in the LT derived from AIRS radiance measurements (expressed in brightness temperature) and by ${ }^{12,38}$ based on model simulations. At the center of the $v_{2}$ (below $700 \mathrm{~cm}^{-1}$ ) and $v_{3}$ (after $\left.2250 \mathrm{~cm}^{-1}\right) \mathrm{CO}_{2}$ bands (and for the $791.75 \mathrm{~cm}^{-1}$ line), all the radiation emitted by the surface is absorbed by the atmospheric $\mathrm{CO}_{2}$ (with the largest percentual changes occurring close to the tropopause around the $80-90 \mathrm{hPa}$ levels (16-17 km, Fig. 1c)). The SOLR observed at the top of the atmosphere corresponds therefore only to the emission of radiations from above in the stratosphere. In these spectral ranges, the increase in $\mathrm{CO}_{2}$ concentrations would thus result in increased SOLR emissions which translates into a positive LT. However, the cooling trend observed indicates that the effect of the stratospheric temperature decrease (Fig. 2l) dominates here. Conversely, in the wings of the $\mathrm{CO}_{2}$ bands and in the $v_{4} \mathrm{CH}_{4}$ band, characterized by lower maximum sensitivity levels $(\sim 350-500 \mathrm{hPa})$, the negative LT in the tropics and at Northern hemispheric mid-latitudes (between $45^{\circ} \mathrm{N}$ and $30^{\circ} \mathrm{S}$ ) reflect the increase in the $\mathrm{CO}_{2}$ and $\mathrm{CH}_{4} \mathrm{IR}$ absorption which shifts the effective emitting level of radiations to higher (and therefore substantially colder) altitudes of the troposphere ${ }^{38,48,49}$. The effect of the tropospheric warming is thus here negated by the $\mathrm{CO}_{2}$ and $\mathrm{CH}_{4}$ increase. This is evidenced on the $\mathrm{LT}$ distribution for the tropospheric $\mathrm{CO}_{2}$ channel at $740.75 \mathrm{~cm}^{-1}$ (Fig. 2c) where homogeneous negative changes are observed between $45^{\circ} \mathrm{N}$ and $\mathrm{S}$, while the temperature LT at the corresponding altitude of sensitivity (Fig. 2i, j) show a more important variability. This indicates that the effect of the $\mathrm{CO}_{2}$ increase is the dominant factor driving the LT. For $\mathrm{N}_{2} \mathrm{O}$, as it was also the case for the $v_{1}$ band in the window region (around $2224 \mathrm{~cm}^{-1}$ ), the effect of increasing concentrations is again not visible in the LT in the $v_{3}$ $\mathrm{N}_{2} \mathrm{O}$ band (around $1230-1320 \mathrm{~cm}^{-1}$ ) due to the overlapping atmospheric variations of $\mathrm{CH}_{4}$.

In the $v_{2} \mathrm{H}_{2} \mathrm{O}$ band (around $1595 \mathrm{~cm}^{-1}$ ), the LT also reflect the changes in the state of the atmosphere at different altitudes. For the mid-tropospheric channels $(\sim 500 \mathrm{hPa}$, Fig. $1 \mathrm{c})$, a pronounced latitudinal structure is found on Fig. 1a between $40^{\circ} \mathrm{N}$ and $\mathrm{S}$ with trends being either positive or negative. The global distribution of the $\mathrm{LT}$ at $1441.25 \mathrm{~cm}^{-1}$ (Fig. $2 \mathrm{~d}$ ) reveals a strong regional pattern. The latter likely reflects the changes in the main convergence (upward motions) and subsidence (sinking motions) zones associated with large-scale atmospheric circulation which carries heat and moisture ${ }^{50}$. Convergence zones are typically associated with a strong local increase of water vapor which increases the amount of radiation absorbed. Its effect on the SOLR (known as super greenhouse effect $(\mathrm{SGE})^{14,50}$ ) exceeds that of the warming of the mid-troposphere and results in a decrease of the SOLR in total. 
Conversely, subsidence zones are characterized by a drying of the air masses which translates into a decrease of the absorption (an increase of the SOLR) in the $v_{2} \mathrm{H}_{2} \mathrm{O}$ band. In particular, this effect is illustrated by the large crescent-shaped positive LT observed in the tropical Western Pacific (Fig. 2d, box 6) which corresponds to a well-known region affected by severe droughts during ENSO events $^{51,52}$. Similar patterns were already observed for the longwave cloud feedbacks ${ }^{53}$, supporting our analysis on the convective processes.

In contrast to the mid-tropospheric channels, the very strong $\mathrm{H}_{2} \mathrm{O}$ absorption channels that have a maximum sensitivity higher in the troposphere (typically $\sim 150-250 \mathrm{hPa}$, Fig. 1c) show systematically negative LT in the tropics and at mid-latitudes (Fig. 1a). For those channels, as it was also the case for the stratospheric $\mathrm{CO}_{2}$ channels, the atmosphere is almost opaque to the surface emissions and a significant fraction of the SOLR emerges from the lower stratosphere. Here, the SOLR decrease are likely the result of two combined effects ${ }^{38}$ : (1) the cooling of the stratosphere in link with the strengthening of the $\mathrm{BDC}$ and the $\mathrm{CO}_{2}$ increase, and (2) the increase of $\mathrm{H}_{2} \mathrm{O}$ concentrations in the upper troposphere that goes along with the rise in tropospheric temperature as a consequence of the Clausius-Clapeyron process. This is confirmed by the LT distribution of the strong $\mathrm{H}_{2} \mathrm{O}$ absorption line at $1507 \mathrm{~cm}^{-1}$ (Fig. 2e) which shows negative trends over most of the tropical and mid-latitude regions. Two regions (boxes in Fig. 2e), though, exhibits a significant positive trend. The first one is located in the Northern Pacific between 30 and $45^{\circ} \mathrm{N}$ and is likely influenced by the warming of the lower stratosphere in the area (Fig. 2k). The second one, found in the Southern Pacific, is not correlated with a temperature increase in the stratosphere and might instead reflect the drying of air masses in the upper troposphere, possibly related to a local subsidence zone.

The $v_{3} \mathrm{O}_{3}$ band (around $1042 \mathrm{~cm}^{-1}$ ) is characterized by strong positive zonal LT comprised between +0.05 and $+0.12 \%$ per year $\left(+0.8\right.$ to $+1.5 \times 10^{-4} \mathrm{~W} \cdot \mathrm{m}^{-2}$ per year), with the strongest changes occurring below $30^{\circ} \mathrm{N}$ and $\mathrm{S}$ (Fig. $1 \mathrm{a}, \mathrm{b}$ ). Between $30^{\circ}$ and $45^{\circ} \mathrm{N}$ and $\mathrm{S}$, close to the center of the band, LT generally do not differ significantly from zero. When looking at the global distribution of the LT for the strong $\mathrm{O}_{3}$ channel at $1057.25 \mathrm{~cm}^{-1}$ (Fig. 2f), we find an important spatial heterogeneity. Between $30^{\circ} \mathrm{N}$ and $\mathrm{S}$, most of the positive LT are observed over the Pacific Ocean. Over the Atlantic, LT are mainly negative while they are close to zero (or not significantly different from zero) above the Indian Ocean. Conversely, the $\left[30^{\circ}-45^{\circ} \mathrm{N}\right.$ and S] regions show large negative patterns in the Pacific, which are compensated in the zonal mean by the positive LT elsewhere. In general, these LT in the tropical and mid-latitude regions do not correspond to the changes observed in the atmospheric temperature at $\sim 50 \mathrm{hPa}$ (Fig. 2l), where the $\mathrm{O}_{3}$ band is mostly sensitive, and this therefore suggests a variation in the $\mathrm{O}_{3}$ concentrations. Over the Pacific Ocean (between $45^{\circ} \mathrm{N}$ and S), the observed LT can be explained by the ENSO cycles. $\mathrm{O}_{3}$ is mainly produced in the tropics in the lower and mid stratosphere and its abundance is directly modulated by the strength of the upwelling motions in the tropical lower stratosphere. During an El Niño event (in particular the 2015-2016 event here), the strengthening of the upwelling of the BDC in the tropics brings more air generally poor in $\mathrm{O}_{3}$ from the troposphere into the stratosphere, leading to a decrease in $\mathrm{O}_{3}$ concentrations in the lower stratosphere (and thus a positive LT for the period considered here $)^{54,55}$. Conversely, over the mid-latitude Pacific (between $30^{\circ}$ and $45^{\circ} \mathrm{N}$ and S), the enhanced downward motions of the BDC lead to an increase of the $\mathrm{O}_{3}$ concentrations which translates into negative $\mathrm{LT}^{55,56}$.

At high latitudes, the interpretation of the LT is easier because most of the changes can be explained by a change in temperature at different altitudes. In the center of the $v_{2}$ and the $v_{3} \mathrm{CO}_{2}$ band, and for the strong $v_{4} \mathrm{CH}_{4}$ and $v_{2} \mathrm{H}_{2} \mathrm{O}$ absorption lines (Fig. 1a, d), almost opaque to the surface emissions, the LT are strongly positive (up to
$0.2-0.4 \%$ per year) above $40^{\circ} \mathrm{S}$ and $55^{\circ} \mathrm{N}$ and reflect the warming of the stratosphere caused by a strengthening of the BDC. In the wings of the $\mathrm{CO}_{2}$ bands, the LT become progressively negative as the atmosphere is more transparent to the surface at these wavenumbers and also because of the $\mathrm{CO}_{2}$ increase. For $\mathrm{H}_{2} \mathrm{O}$, apart from the strong lines in the center of the $v_{2}$ band, the LT appear mostly not significantly different from zero. Finally, in the $v_{3} \mathrm{O}_{3}$ band, the LT observed probably reflect the opposite effects of the stratospheric warming and the $\mathrm{O}_{3}$ increase, the latter being likely due to both the strengthening of the $\mathrm{BDC}^{55,56}$ and the stratospheric ozone recovery at $20-25 \mathrm{~km}$ of altitude $44,57,58$. This is especially evident in the center of the band, where both impacts almost cancel each other out (LT close to zero) (Fig. 1d). When moving away from the center, the LT become more negative because of the larger fraction of the signal coming from the surface.

\section{DISCUSSION}

Making use of 10 years (2008-2017) of IASI measurements, we have estimated the linear trends (LT) in zonally averaged spectrally resolved OLR (SOLR) at a spectral sampling of $0.25 \mathrm{~cm}^{-1}(6621$ channels in total). The LT result from both the atmospheric composition and temperature changes. Despite the limited time period and the difficulty of disentangling the effect of the different parameters affecting the SOLR, clear spectral signatures of the long-term changes in greenhouse gases concentrations (in particular $\mathrm{CO}_{2}, \mathrm{CH}_{4}$ but also CFC-11 and CFC-12) could be identified unambiguously, especially in channels sensitive to the mid- and upper troposphere. For $\mathrm{CO}_{2}$ and $\mathrm{CH}_{4}$, the increase in the atmospheric concentrations resulted in an increase of the fraction of SOLR absorbed which translated into a negative LT of about -0.05 to $-0.3 \%$ per year in the $v_{2}$ and $v_{3} \mathrm{CO}_{2}$ and in the $v_{4} \mathrm{CH}_{4}$ absorption band. For the LT mainly reflecting the changes in atmospheric temperature, most of them may have been connected to changes in the atmospheric circulation originating from an increase of the SST driven by the ENSO and PDO activity. In particular, the LT for the $v_{2} \mathrm{H}_{2} \mathrm{O}$ mid-tropospheric sensitive channels revealed a strong regional pattern reflecting the changes in the main convergence and subsidence zones. In the three atmospheric window regions, the LT at high latitudes (above $60^{\circ} \mathrm{N}$ and S) were associated with high uncertainties because of the low number of observations and possible issues with the cloud filter. All these results show the potential of the IASI-derived spectrally resolved OLR in improving our understanding of the current Earth's climate and of its long-term changes. In particular, such high spectral sampling - never reached before with any satellitederived OLR - is of great interest for the identification of errors and biases of opposite sign in the output of climate models that cancel each other in total OLR. With the launch of IASI on Metop-B in 2012 and on Metop-C in 2018, which L1C product is consistent with the reprocessed IASI-A radiance dataset ${ }^{22}$, and the future launch of IASI-NG (New Generation, with a spectral sampling of $0.125 \mathrm{~cm}^{-1}$ ) on the Metop-SG suite of satellites, the time series of spectrally resolved OLR will be extended by at least another 25 years of measurements.

\section{METHOD}

\section{Data}

The clear-sky SOLR are derived from a complete reprocessed dataset of IASI/Metop-A radiance measurements (with the latest version of the $L 1 C)^{22}$ in the range $645-2300 \mathrm{~cm}^{-1}$ at the $0.25 \mathrm{~cm}^{-1}$ native spectral sampling of the L1C spectra. The algorithm for the conversion of the spectra to the fluxes is detailed in Whitburn et al. ${ }^{28}$. The SOLR are derived with a good precision generally within $\pm 0.005 \mathrm{~W} \mathrm{~m}^{-2}\left(\mathrm{~cm}^{-1}\right)^{-1}$ depending on the wavenumber. The $2300 \mathrm{~cm}^{-1}$ upper bound was chosen to avoid solar reflectance contamination. The cloud-free scenes were selected based on the cloud information from the Advanced Very High Resolution 
Radiometer (AVHRR) flying on board the MetOp satellites as well. Only IASI observations associated with a $0 \%$ cloud coverage were considered. The cloud flag is rather conservative, keeping only $\sim 14 \%$ of all observations. The distribution of the fraction of clear-sky scenes is shown in Supplementary Fig. 2. The raw dataset consists of 10 years of daily global SOLR (2008-2017) averaged on a $2^{\circ} \times 2^{\circ}$ grid, separately for day and night observations. For our analysis, we focused on daytime measurements. We restricted the analysis to observations over sea to ensure capturing trends related to global climate phenomena. Indeed, measurements over land are subject to stronger local variations in space and time (especially for the channels that are significantly influenced by the lower layers of the atmosphere and the surface) because of the smaller heat capacity compared to seas and the larger heterogeneity of the surface parameters (e.g. orography and land cover). These variations make it more difficult to identify changes in the SOLR on larger scales, in particular when focusing on relatively short time periods, such as those considered here.

\section{Trends estimation}

For each IASI channel, linear trends (LT) were computed from the daily SOLR, averaged zonally by $2^{\circ}$ latitude, using the approach described in Gardiner et al. $^{59}$. The method relies on fitting a low order Fourier series (here $n=3$ ) capturing the intra-annual variability in the SOLR plus a linear term (the annual trend) to the dataset. The confidence limits associated with the trend estimates are determined using a bootstrap resampling. A LT is considered significantly different from zero if the $95 \%$ confidence interval does not contain zero. Even though land measurements were filtered out, their influence on the calculated zonal trends remains, especially near the coasts, as changes that occur over land can propagate over oceans. In addition to this, another effect that likely influences the zonal trends is the heterogeneity in the distribution of the cloud-free observations (see Supplementary Fig. 2) which modulates the weight of each region when averaging the SOLR by band of latitude. The impact of the zonal variability in the SOLR and of the heterogeneity in the cloud distribution are reflected in the uncertainties in the zonal linear trend. Nevertheless, these limitations have to be kept in mind for the analysis of the results.

\section{DATA AVAILABILITY}

Monthly means of IASI-derived spectrally resolved $O \mathrm{LR}^{60}$ are freely available for all users through the IASI-FT website: https://iasi-ft.eu/data-access/OLR/.

Daily IASI-derived spectrally resolved OLR can be made available upon request to the corresponding author.

\section{CODE AVAILABILITY}

The analysis codes can be made available upon request to the corresponding author.

Received: 8 April 2021; Accepted: 27 September 2021; Published online: 22 October 2021

\section{REFERENCES}

1. Dewitte, S. \& Clerbaux, N. Decadal changes of earth's outgoing longwave radiation. Remote Sens. 10, 1539 (2018).

2. Allan, R. P. \& Ringer, M. A. Inconsistencies between satellite estimates of longwave cloud forcing and dynamical fields from reanalyses. Geophys. Res. Lett. 30, 9 (2003).

3. Chung, E.-S., Yeomans, D. \& Soden, B. J. An assessment of climate feedback processes using satellite observations of clear-sky OLR. Geophys. Res. Lett. 37, L02702 (2010).

4. Trenberth, K. E., Fasullo, J. T., O'Dell, C. \& Wong, T. Relationships between tropical sea surface temperature and top-of-atmosphere radiation. Geophys. Res. Lett. 37, L03702 (2010).

5. Allan, R. P. et al. Changes in global net radiative imbalance 1985-2012. Geophys. Res. Lett. 41, 5588-5597 (2014).

6. Dewitte, S. Editorial for special issue "earth radiation budget". Remote Sens. 12, 3379 (2020).

7. Kramer, R. J., Matus, A. V., Soden, B. J. \& L'Ecuyer, T. S. Observation-based radiative kernels from CloudSat/CALIPSO. J. Geophys. Res. Atmos. 124, 5431-5444 (2019).

8. Kramer, R. J. et al. Observational evidence of increasing global radiative forcing. Geophys. Res. Lett. 48, e2020GL091585 (2021).
9. Loeb, N., Thorsen, T., Norris, J., Wang, H. \& Su, W. Changes in earth's energy budget during and after the "pause" in global warming: an observational perspective. Climate 6, 62 (2018).

10. Slingo, A. \& Webb, M. J. The spectral signature of global warming. Quart. J. Roy. Meteor. Soc. 123, 293-307 (1997).

11. Harries, J. E., Brindley, H. E., Sagoo, P. J. \& Bantges, R. J. Increases in greenhouse forcing inferred from the outgoing longwave radiation spectra of the Earth in 1970 and 1997. Nature 410, 355-357 (2001).

12. Brindley, H. E. \& Bantges, R. J. The spectral signature of recent climate change. Curr. Clim. Change Rep. 2, 112-126 (2016).

13. Huang, Y., Ramaswamy, V., Huang, X., Fu, Q. \& Bardeen, C. A strict test in climate modeling with spectrally resolved radiances: GCM simulation versus AIRS observations. Geophys. Res. Lett. 34, L24707 (2007).

14. Huang, Y. \& Ramaswamy, V. Observed and simulated seasonal co-variations of outgoing longwave radiation spectrum and surface temperature. Geophys. Res. Lett. 35, L17803 (2008).

15. Huang, X., Yang, W., Loeb, N. G. \& Ramaswamy, V. Spectrally resolved fluxes derived from collocated AIRS and CERES measurements and their application in model evaluation: Clear sky over the tropical oceans. J. Geophys. Res. 113, D09110 (2008).

16. Huang, X., Loeb, N. G. \& Yang, W. Spectrally resolved fluxes derived from collocated AIRS and CERES measurements and their application in model evaluation: 2. Cloudy sky and band-by-band cloud radiative forcing over the tropical oceans. J. Geophys. Res. 115, D21101 (2010).

17. Aumann, H. H. et al. AIRS/AMSU/HSB on the aqua mission: design, science objectives, data products, and processing systems. IEEE Trans. Geosci. Remote Sens. 41, 253-264 (2003).

18. Pan, F., Huang, X., Strow, L. L. \& Guo, H. Linear trends and closures of 10-yr observations of AIRS stratospheric channels. J. Clim. 28, 8939-8950 (2015).

19. Clerbaux, C. et al. Monitoring of atmospheric composition using the thermal infrared IASI/MetOp sounder. Atmos. Chem. Phys. 9, 6041-6054 (2009).

20. Hilton, F. et al. Hyperspectral earth observation from IASI: five years of accomplishments. Bull. Am. Meteorol. Soc. 93, 347-370 (2012).

21. Han, Y. et al. Suomi NPP CrIS measurements, sensor data record algorithm, calibration and validation activities, and record data quality. J. Geophys. Res. Atmos. 118, 12734-12748 (2013).

22. Bouillon, M. et al. Ten-year assessment of IASI radiance and temperature. Remote Sens. 12, 2393 (2020).

23. Saunders, R. W., Blackmore, T. A., Candy, B., Francis, P. N. \& Hewison, T. J. Ten years of satellite infrared radiance monitoring with the met office NWP model. IEEE Trans. Geosci. Remote Sens. 59, 4561-4569 (2021).

24. Goldberg, M. et al. The global space-based inter-calibration system. Bull. Am. Meteorol. Soc. 92, 467-475 (2011).

25. Hewison, T. J. et al. GSICS inter-calibration of infrared channels of geostationary imagers using metop/IASI. IEEE Trans. Geosci. Remote Sens. 51, 1160-1170 (2013).

26. Brindley, $\mathrm{H}$. et al. Spectral signatures of earth's climate variability over 5 years from IASI. J. Clim. 28, 1649-1660 (2015).

27. Bantges, R. J. et al. On the detection of robust multidecadal changes in earth's outgoing longwave radiation spectrum. J. Clim. 29, 4939-4947 (2016).

28. Whitburn, S. et al. Spectrally resolved fluxes from IASI data: retrieval algorithm for clear-sky measurements. J. Clim. 33, 6971-6988 (2020).

29. Anderson, G., Clough, S., Kneizys, F., Chetwynd, J. \& Shettle, E. P. AFGL Atmospheric Constituent Profiles (0-120 km), AFGL-TR-86-0110. Hanscom AFB, MA: Optical Physics Division, Air Force Geophysics Laboratory (1986).

30. Coheur, P.-F. et al. Retrieval and characterization of ozone vertical profiles from a thermal infrared nadir sounder. J. Geophys. Res. 110, D24303 (2005).

31. Hersbach, H. et al. The ERA5 global reanalysis. Q. J. R. Meteorol. Soc. 146, 1999-2049 (2020).

32. United States Climate Prediction Center. Historical El Niño episodes (1950-present). https://origin.cpc.ncep.noaa.gov/products/analysis_monitoring/ ensostuff/ONI_v5.php (2020). Accessed on 17 December 2020.

33. Mantua, N. J. \& Hare, S. R. The pacific decadal oscillation. J. Oceanogr. 58, 35-44 (2002).

34. National Centers for Environmental Information (NOAA). Pacific Decadal Oscillation (PDO). https://www.ncdc.noaa.gov/teleconnections/pdo (2020). Accessed on 17 December 2020.

35. Messié, M. \& Chavez, F. Global modes of sea surface temperature variability in relation to regional climate indices. J. Clim. 24, 4314-4331 (2011).

36. Rahmstorf, S. et al. Exceptional twentieth-century slowdown in Atlantic Ocean overturning circulation. Nat. Clim. Change 5, 475-480 (2015).

37. Yuan, X. ENSO-related impacts on Antarctic sea ice: a synthesis of phenomenon and mechanisms. Antarct. Sci. 16, 415-425 (2004).

38. Huang, Y. \& Ramaswamy, V. Evolution and trend of the outgoing longwave radiation spectrum. J. Clim. 22, 4637-4651 (2009). 
39. World Meteorological Organisation. Scientific Assessment of Ozone Depletion: 2018. techreport 58. Global Ozone Research and Monitoring Project-Report No. 58. Geneva, Switzerland (2018).

40. Hu, Y. \& Fu, Q. Stratospheric warming in Southern Hemisphere high latitudes since 1979. Atmos. Chem. Phys. 9, 4329-4340 (2009).

41. Garfinkel, C. I., Waugh, D. W., Oman, L. D., Wang, L. \& Hurwitz, M. M. Temperature trends in the tropical upper troposphere and lower stratosphere: connections with sea surface temperatures and implications for water vapor and ozone. J. Geophys. Res. Atmos. 118, 9658-9672 (2013).

42. Fu, Q., Lin, P., Solomon, S. \& Hartmann, D. L. Observational evidence of strengthening of the Brewer-Dobson circulation since 1980. J. Geophys. Res. Atmos. 120, 10,214-10,228 (2015).

43. Lin, J. \& Qian, T. Impacts of the ENSO lifecycle on stratospheric ozone and temperature. Geophys. Res. Lett. 46, 10646-10658 (2019).

44. Xia, Y., Xu, W., Hu, Y. \& Xie, F. Southern-Hemisphere high-latitude stratospheric warming revisit. Clim. Dyn. 54, 1671-1682 (2019).

45. Santer, B. D. Behavior of tropopause height and atmospheric temperature in models, reanalyses, and observations: decadal changes. J. Geophys. Res. 108, ACL 1-1-ACL 1-22 (2003).

46. Lin, P., Fu, Q. \& Hartmann, D. L. Impact of tropical SST on stratospheric planetary waves in the southern hemisphere. J. Clim. 25, 5030-5046 (2012).

47. Randel, W. J. \& Cobb, J. B. Coherent variations of monthly mean total ozone and lower stratospheric temperature. J. Geophys. Res. 99, 5433 (1994).

48. Strow, L. L. \& DeSouza-Machado, S. Establishment of AIRS climate-level radiometric stability using radiance anomaly retrievals of minor gases and sea surface temperature. Atmos. Meas. Tech. 13, 4619-4644 (2020).

49. Kiehl, J. T. Satellite detection of effects due to increased atmospheric carbon dioxide. Science 222, 504-506 (1983).

50. Bony, S., Lau, K.-M. \& Sud, Y. C. Sea surface temperature and large-scale circulation influences on tropical greenhouse effect and cloud radiative forcing. $J$. Clim. 10, 2055-2077 (1997).

51. McPhaden, M. J. The Earth System: Physical and Chemical Dimensions of Global Environmental Change. (eds MacCracken, M. C. \& Perry, J. S.) Vol. 1. Encyclopedia of Global Environmental Change, p. 353-370 (John Wiley and Sons, 2002).

52. Raghuraman, S. P., Paynter, D. \& Ramaswamy, V. Quantifying the drivers of the clear sky greenhouse effect, 2000-2016. J. Geophys. Res. Atmos. 124, 11354-11371 (2019).

53. Dessler, A. E. Observations of climate feedbacks over 2000-10 and comparisons to climate models. J. Clim. 26, 333-342 (2013).

54. Randel, W. J., Garcia, R. R., Calvo, N. \& Marsh, D. ENSO influence on zonal mean temperature and ozone in the tropical lower stratosphere. Geophys. Res. Lett. 36, 15 (2009).

55. Diallo, M. et al. Response of stratospheric water vapor and ozone to the unusual timing of El Niño and the QBO disruption in 2015-2016. Atmos. Chem. Phys. 18, 13055-13073 (2018)

56. Neu, J. L. et al. Tropospheric ozone variations governed by changes in stratospheric circulation. Nat. Geosci. 7, 340-344 (2014).

57. Philipona, R. et al. Radiosondes show that after decades of cooling, the lower stratosphere is now warming. J. Geophys. Res. Atmos. 123, 12509-12522 (2018)

58. Wespes, $\mathrm{C}$. et al. Is the recovery of stratospheric $\mathrm{O}_{3}$ speeding up in the Southern Hemisphere? An evaluation from the first IASI decadal record (2008-2017). Atmos. Chem. Phys. 19, 14031-14056 (2019).

59. Gardiner, T. et al. Trend analysis of greenhouse gases over Europe measured by a network of ground-based remote FTIR instruments. Atmos. Chem. Phys. 8, 6719-6727 (2008).

60. Whitburn, S. IASI-FT spectrally resolved Outgoing Longwave Radiation (from IASI) Metop-A). ULB/LATMOS (2021).

\section{ACKNOWLEDGEMENTS}

IASI has been developed and built under the responsibility of the Centre National d'Études spatiales (CNES, France). It is flown on board the Metop satellites as part of the EUMETSAT Polar System. The IASI L1C data are received through the EUMETCast near-real-time data distribution service. This project has received funding from the European Research Council (ERC) under the European Union's Horizon 2020 research and innovation program (grant agreement No. 742909, IASI-FT advanced ERC grant). It was also supported by the Prodex arrangement IASI.FLOW (Belspo-ESA). Simon Whitburn is grateful to the ERC for funding his research work. L.C. is a research associate (Chercheur Qualifié) supported by the Belgian F.R.S.-FNRS. C.C. is grateful to CNES for scientific collaboration and financial support. H.DeL. is grateful for her PhD grant to the "Fonds pour la Formation à la Recherche dans I'Industrie et dans I'Agriculture" of Belgium. We acknowledge EUMETSAT and the AERIS data infrastructure (https://www.aeris-data.fr/) for providing access to the reprocessed IASI L1C data record.

\section{AUTHOR CONTRIBUTIONS}

S.W. and L.C. conceptualized the study. S.W. also performed the analysis, interpreted the data, and drafted the paper. M.B. prepared the ERA-5 temperature trends maps. All authors contributed to the discussions and the manuscript writing.

\section{COMPETING INTERESTS}

The authors declare no competing interests.

\section{ADDITIONAL INFORMATION}

Supplementary information The online version contains supplementary material available at https://doi.org/10.1038/s41612-021-00205-7.

Correspondence and requests for materials should be addressed to Simon Whitburn.

Reprints and permission information is available at http://www.nature.com/ reprints

Publisher's note Springer Nature remains neutral with regard to jurisdictional claims in published maps and institutional affiliations.

Open Access This article is licensed under a Creative Commons Attribution 4.0 International License, which permits use, sharing, adaptation, distribution and reproduction in any medium or format, as long as you give appropriate credit to the original author(s) and the source, provide a link to the Creative Commons license, and indicate if changes were made. The images or other third party material in this article are included in the article's Creative Commons license, unless indicated otherwise in a credit line to the material. If material is not included in the article's Creative Commons license and your intended use is not permitted by statutory regulation or exceeds the permitted use, you will need to obtain permission directly from the copyright holder. To view a copy of this license, visit http://creativecommons. org/licenses/by/4.0/.

(c) The Author(s) 2021 